\title{
Kabataş-Mecidiyeköy Metro (İstanbul) Tünellerinde Zor Zemin Koşullarının Tünel Kazısına Etkisi
}

\author{
Effect of Difficult Ground Conditions on Tunnel Excavations in Kabataş-Mecidiyekoy Metro \\ (Istanbul) Tunnel
}

Mehmet ÖZÇELIK (D)

Süleyman Demirel Üniversitesi, Mühendislik Fakültesi, Jeoloji Mühendisliği Bölümü, ISPARTA

\section{ÖZ}

Son yıllarda ulaşım tünelleri mekanik yöntemlerle açılmaktadır. Verimli bir tünel kazısının gerçekleştirilebilmesi için jeolojik yapıya uygun kazı makinasının seçimi önemli bir etkendir. Bu makalede, Kabataş-Mecidiyeköy tünel güzergahındaki jeolojik formasyonlar kazı mekaniği açısından değerlendirilmiştir. Kabataş-Mecidiyeköy istasyonları arasındaki İstanbul Metro Projesi, Tünel açma makineleri (TBM) ve Yeni Avusturya Tünel Açma Yöntemi (NATM) olmak üzere iki tip tünel kazısını içermektedir. TBM kullanılarak açılacak olan tünelin iki hattının toplam uzunluğu $6180 \mathrm{~m}$ dir. Ayrıca, NATM yöntemiyle açılacak olan iki hattın toplam uzunluğu ise $4490 \mathrm{~m}$ dir. Çalışma kapsamında, Kabataş-Mecidiyeköy tünel güzergahındaki zemin ve kayaç birimlerinin mühendislik jeolojisi çalışılmış, tünel kayacı olması açısından sınıflandırılmıştır. Zor zemin koşullarının tünel kazı çalışmalarına etkisi incelenmiştir. Ayrıca, jeolojik birimlerin geçirimlilikleri ve yeraltı suyu seviyesi hakkında bilgi verilmiştir.

Anahtar Kelimeler: İstanbul, Jeolojik yapı, Metro, Tünel kazısı

\begin{abstract}
In recent years, transportation tunnels have been excavated by mechanical methods. The selection of a suitable excavator for the geological structure is an important factor in achieving an efficient tunnel excavation. For this purpose, geological formations along the Kabatass-Mecidiyeköy tunnel alignment have been evaluated in terms of excavation mechanics. The Istanbul Metro Project between Kabatas-Mecidiyekoy stations includes two types of tunnel excavations, tunnel boring machines (TBM) and New Austrian Tunneling Method (NATM). The total length of the two lines of the tunnel to be opened using TBM is $6180 \mathrm{~m}$. In addition, the total length of the two lines to be opened by NATM method is $4490 \mathrm{~m}$. In this study, soil and rock units along the Kabataş-Mecidiyeköy tunnel alignment were classified in terms of engineering geology, and tunneling, and the effects of difficult ground conditions on tunnel excavation were investigated. In addition, the related information is given for the permeability of the geological units and the groundwater level.
\end{abstract}

Keywords: Istanbul, Geological structure, Metro, Tunnel excavation 
Özçelik

\section{GİRIŞ}

Kentsel alanlarda yapilan metro çalışmalarında alt ve üst yapıların zarar görmemesi için kullanılacak kazı yönteminin seçimi önemlidir. Metro kazıları TBM, NATM, aç-kapa tünel gibi inşaat yöntemlerinin biri veya birkaçı uygulanarak gerçekleştirilmektedir. Planlanan yeraltı mühendislik yapılarının tasarımında jeolojik yapıya aktarılacak yükler yeterli duyarlılıkta belirlenebilmelidir. Bununla birlikte, kazı sırasında jeolojik yapının oluşturabileceği risklerde (şev kayması, tünel göçmesi, derin kazı çukurlarında aşırı deformasyon ve oturma, aşırı su gelimi vb.) minimize edilmelidir (Arığlu vd., 2002). Ayrıca jeolojik yapı, tünel açma işlemlerinde tünelin zamanında ve başarılı olarak açılmasındaki önemli parametrelerden biridir. Son y1llarda dünyada birçok projede kullanılan TBM'ler ilerleme sırasında oluşan gerilmeleri, sağlam kayanın basınç direnci düzeyine yaklaştırırlar. Yeraltında karşılaşılan jeolojik birimlerin türü TBM' lerin ilke olarak aynı, fakat ayrıntıda çeşitli yönlerden farklı olmasını gerektirmiştir. Örneğin, kullanılacak kafa tasarımları ve keski tipleri, makinayı dengeleme sistemleri, tahkimat sistemleri, çıkarılan pasayı taşıma sistemleri çeşitli yönlerden sert, orta sert, yumuşak ve akıc1 jeolojik birimler için farklılıklar göstermektedir. Bir tünel yapımında TBM kullanımı öncesi jeolojik yapının araştırılması geleneksel tünel açma yöntemlerinden daha ayrıntılı olmalıdır. Kaya sertliği ile ilgili özgül problemler, kaya tabakalarının duruş ve değişimi, kayacın dayanma süresi tünel açma makinesinin başarısını etkileyen önemli öğelerdendir (Deere vd., 1974). Sonuçta, açılacak yeraltı açıklığı boyunca kazılacak jeolojik birimlerin önceden bilinmesi, kullanılacak TBM seçiminde en önemli etmenlerden biri olmuştur (Tunçdemir, 1998). TBM' lerin bilinçli seçilmesi ve kullanımı; hızlı, ekonomik ve verimli tünel ve galeri açmanın en temel unsurudur. Mecidiyeköy - Kabataş istasyonları arasındaki İstanbul Metro Projesi, TBM ve NATM tünel açma yöntemleri olmak üzere iki tünel kazı tipini içermektedir. Metro güzergahında 4 istasyon yer almaktadır. İki hat olarak açılan tüneller, NATM tünel delme yöntemi (4490 m) ve TBM yöntemiyle (6180 m) kazılmaktadır. Ek olarak muhtelif lokasyonlarda inşaat şaftları, TBM giriş şaftları gibi yapılar yer almaktadır. İstasyonların tamamı yüzeye yakın olmakla beraber yeraltındadir. Genel olarak ray hatt1, peron seviyesi ile bunlara bağlanan merdiven grupları delme tüneldedir. Peron ile bilet holü arasındaki ara katlar genellikle aç-kapa yöntemiyle yapılmaktadır. Bilet holü/konkors seviyesi aç-kapa inşaat yöntemi kapsamındadır.

Bu çalışmada seçilen, Kabataş-Mecidiyeköy tünel güzergahındaki (Şekil 1) zemin ve kayaç birimlerinin mühendislik jeolojisi incelenmiş, tünel kayacı olması açısından bunlar sınıflandırılmıştır. NATM yöntemiyle açılacak olan şaft, peron tünelleri, makas tünelleri ve bağlantı tünelleri ile TBM kullanılarak yapılacak olan ana hat kazı çalışmalarında zor zemin koşullarının etkisi incelenmiştir. 


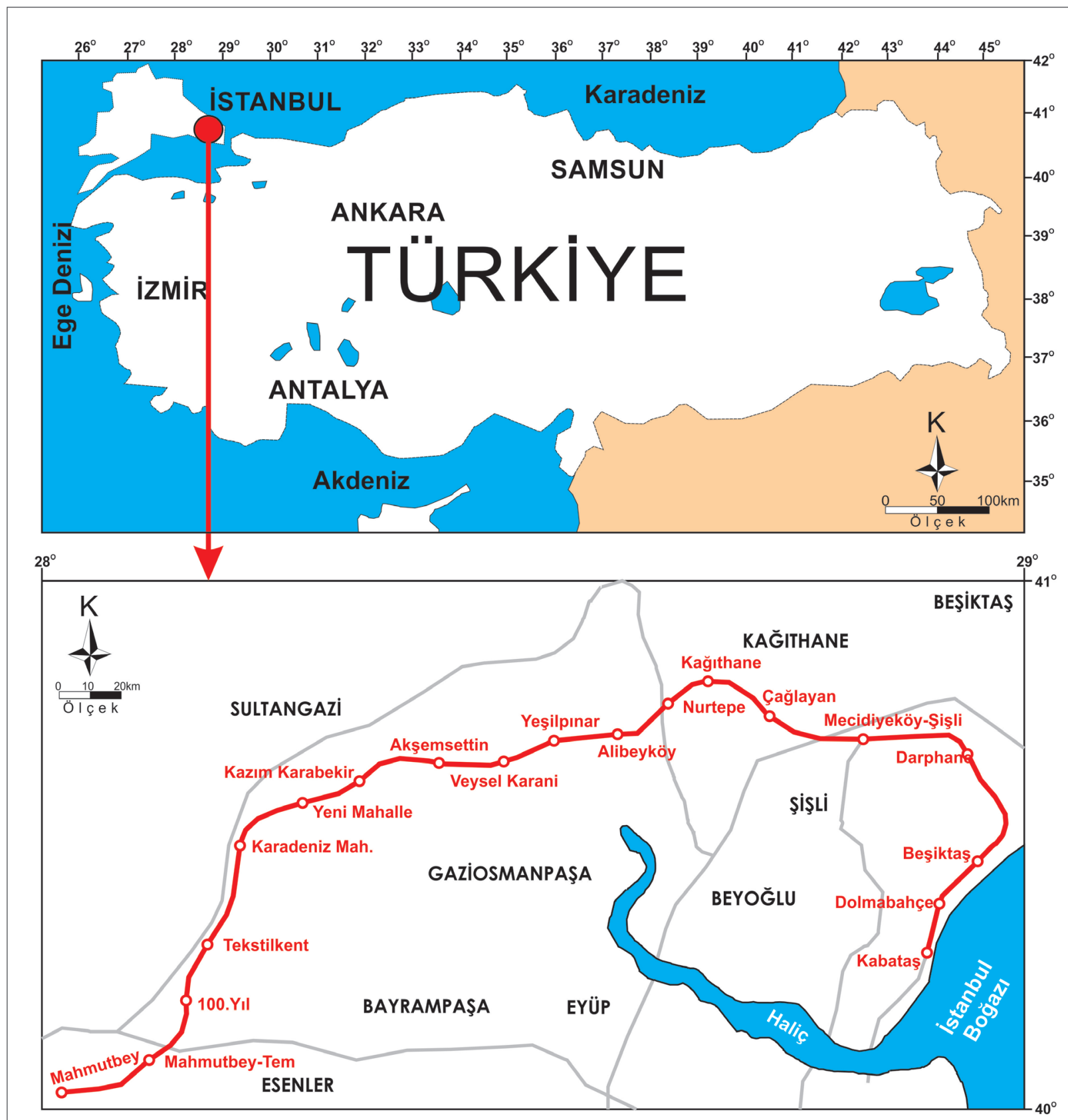

Şekil 1. Kabataş-Mahmutbey istasyonları arasındaki İstanbul Metro Projesi lokasyon haritası.

Figure 1. Location map of Istanbul Metro Project between Kabataş and Mahmutbey stations. 
Özçelik

\section{JEOLOJI}

Çalışma alanı jeolojik olarak Trakya ve Ceylan formasyonlarından oluşmaktadır (Şekil 2). Trakya formasyonu genel olarak kumtaş1, silttaşı, çamurtaşı ve kiltaşı birimleri ve bunların ardalanmasindan meydana gelmektedir. Formasyon içerisinde kalınlıkları 2-3 m olan ve nadiren 50-60 m'ye ulaşan diyabaz ve andezit dayklar1 yer almaktadır (Ketin, 1991; Seymen, 1995). Çoğunlukla oldukça ve tamamen ayrışmış olan bu magmatik sokulumlar, kazı sirasinda fazla güçlük çıkarmamaktadır. Ancak ayrışmamış ve diyabaz bileşimli olanlar ise önemli kazı güçlüğü yaratmaktadır. Trakya formasyonu'nun kıvrımlı ve kırıklı bir yapı sunduğu aşırı derecede kırıklandığ1 ve parçalandığ1 görülmektedir. Plastik davranış gösterme özelliği nedeniyle kiltaşı ve çamurtaşı birimleri aşırı derecede kıvrımlanırken, daha rijit olan kumtaşları kırılarak yer yer budinler oluşturmuşlardır. $\mathrm{Bu}$ formasyon, yüzeyden ortalama $3 \mathrm{~m}$ derinliğe kadar yapay dolgunun altindadir ve yine yüzeyden 10-15 m derinliğe kadar orta veya aşırı derecede ayrışmıştır. Kumtaşı tabakaları silttaşı veya kiltaşı düzeylerine göre daha kalın katmanlıdır $(5-50 \mathrm{~cm})$. Silttaşı ve kiltaş1 düzeylerinin ortalama kalınlıkları $1-10 \mathrm{~cm}$ arasında değişmektedir. Tabaka yüzeyleri genelde düz-düzlemsel, kaygan veya az pürüzlü (özellikle kumtaşları) olup, kil ile sıvalıdır. Tabakalar dışındaki süreksizlik düzlemlerini; eklem takımları, faylar, makaslamalar ve düzensiz kırıklar oluşturmaktadır. Özellikle tünel ve istasyon kazıları esnasında 2-3 adet eklem takımı ve bunların yanında düzensiz çatlaklar izlenmiştir. Çatlak sıklıkları ortalama 5-20 adet/m dir (kırıklı, çok kırıklı kayaç). Çatlak yüzeyleri çoğunlukla düz ve kaygandır. Ancak yer yer özellikle kumtaşı çatlaklarında az pürüzlü yüzeyler gözlenmektedir. Çatlak aralıkları çoğunlukla mm mertebesinde ve kil ile dolguludur (Ketin, 1991; Seymen, 1995).

Çalışma sahasının yerleşim yeri olmasından dolayı tünel güzergahını temsil edecek sayıda mostra bulunamamış ve istenilen oranda çatlak ölçümü yapılamamıştır. Ancak Trakya formasyonu'ndaki tünel kazısı çalışmalarında aynada gerçekleştirilen çatlak ölçümleri Çizelge 1'de gösterilmiştir. Şekil 3'de çatlak sistemlerinin Gül diyagramında tünel ekseni ile olan ilişkisi gösterilmiştir. Şekil 4'de ise Eşit Alan (Schmidt) diyagramı verilmiştir. Burada çatlak düzlemlerine ait doğrultuların $\mathrm{KB}$ ve $\mathrm{KD}$, eğim yönlerinin ise KD-GB yönlerinde yoğunlaştığı görülmektedir. 


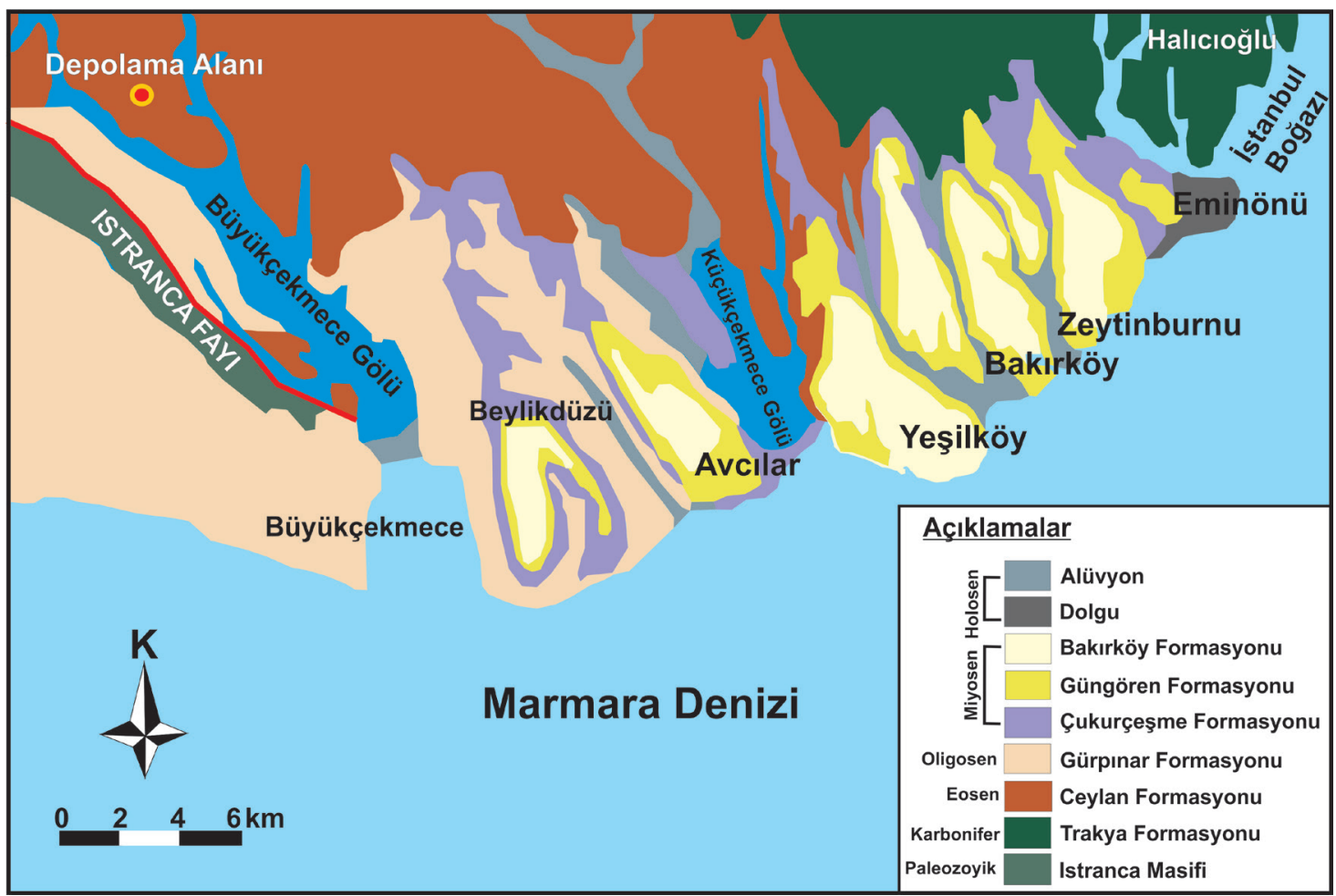

\begin{tabular}{|c|c|c|c|c|}
\hline Zaman & Devir & Alt Devir & Litoloji & Litolojik Özellik \\
\hline \multirow{6}{*}{ 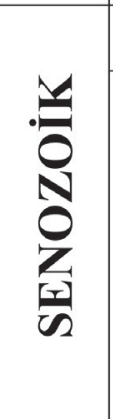 } & \multicolumn{2}{|c|}{ KUVATERNER } & & $\begin{array}{l}\text { ALÜVYON } \\
\text { Çakıl, Kum, Silt, Kil }\end{array}$ \\
\hline & \multirow{6}{*}{ 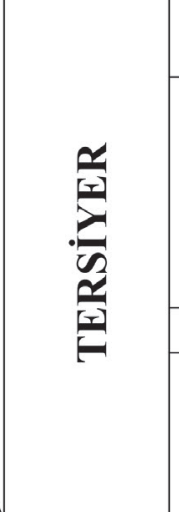 } & PLİOSEN & & $\begin{array}{l}\text { DOLGU MALZEMESİ } \\
\text { Kuvars Çakıllı Kil, Silt }\end{array}$ \\
\hline & & \multirow{3}{*}{ MIYYOSEN } & & $\begin{array}{l}\text { BAKIRKÖY FORMASYONU } \\
\text { Kireçtaș1 }\end{array}$ \\
\hline & & & & $\begin{array}{l}\text { GÜNGÖREN FORMASYONU } \\
\text { Marn Aratabakalı Kil }\end{array}$ \\
\hline & & & & $\begin{array}{l}\text { ÇUKURCCESME FORMASYONU } \\
\text { Siltli Killi Kum, Kum }\end{array}$ \\
\hline & & OLIGOSEN & & GÜRPINAR FORMASYONU İnce bantlı Kil \\
\hline \multirow{2}{*}{ 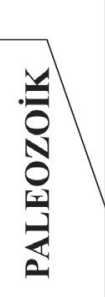 } & & $\begin{array}{l}\text { ORTA-ÜST } \\
\text { EOSEN }\end{array}$ & & $\begin{array}{l}\text { CEYLAN FORMASYONU } \\
\text { Kalkerli Kil, Killi Kireçtaşı, Kalkarenit, Killi Çakııllı Kum, Kumlu Kil } \\
\text { Kırıklareli Kireçtaşı, Resifal Kireçtaşı, Marnlı Kireçtaşı }\end{array}$ \\
\hline & KARBONIFER & & & $\begin{array}{l}\text { TRAKYA FORMASYONU } \\
\text { Kumtașı, Silttașı, Çamurtaşı, Kiltaşı }\end{array}$ \\
\hline
\end{tabular}

Şekil 2. İstanbul'un batı yakasının jeoloji haritası ve stratigrafik kolon kesiti (Arıç, 1955; Dalgıç, 2004; Güven, 2009). Figure 2. Geological map and stratigraphic columnar section of the western side of Istanbul (Arlç, 1955; Dalgıc, 2004; Güven, 2009). 
Özçelik

Çizelge 1. Kazı aşamasında Trakya formasyonu'nda aynada yapılan süreksizlik ölçümleri.

Table 1. Discontinuity measurements at the tunnel face during the excavation stage in the Thrace formation.

\begin{tabular}{|c|c|c|c|}
\hline \multirow[t]{2}{*}{ Lokasyon No } & \multirow[t]{2}{*}{ Çatlak sistemleri } & \multicolumn{2}{|c|}{ Tabaka } \\
\hline & & Doğrultu & Eğim açısı \\
\hline L-05 Hatt1 & K48B/40KD & K40D & $25 \mathrm{GD}$ \\
\hline L-05 Hatt1 & K46B/38KD & K55D & $32 \mathrm{GD}$ \\
\hline L-05 Hatt1 & $\mathrm{K} 45 \mathrm{~B} / 41 \mathrm{KD}$ & K50D & $30 \mathrm{GD}$ \\
\hline L-05 Hatt1 & K44B/40KD & K60D & $45 \mathrm{GD}$ \\
\hline L-05 Hatt1 & $\mathrm{K} 46 \mathrm{~B} / 40 \mathrm{KD}$ & K48D & 70GD \\
\hline L-05 Hatt1 & $\mathrm{K} 48 \mathrm{~W} / 38 \mathrm{KD}$ & K53D & $68 \mathrm{GD}$ \\
\hline L-05 Hatt1 & $\mathrm{K} 85 \mathrm{D} / 80 \mathrm{GD}$ & K73D & $45 \mathrm{GD}$ \\
\hline L-05 Hatt1 & $\mathrm{K} 45 \mathrm{~B} / 41 \mathrm{KD}$ & K40D & $25 \mathrm{GD}$ \\
\hline L-05 Hatt1 & $\mathrm{K} 45 \mathrm{~B} / 40 \mathrm{KD}$ & K50D & 48GD \\
\hline L-05 Hatt1 & K44B/39KD & K60D & $45 \mathrm{GD}$ \\
\hline L-05 Hatt1 & $\mathrm{K} 44 \mathrm{~B} / 42 \mathrm{KD}$ & K44D & 40GD \\
\hline L-05 Hatt1 & $\mathrm{K} 43 \mathrm{~B} / 40 \mathrm{KD}$ & K38D & $63 \mathrm{GD}$ \\
\hline L-05 Hatt1 & $\mathrm{K} 29 \mathrm{~B} / 21 \mathrm{KD}$ & K48D & $77 \mathrm{~KB}$ \\
\hline L-05 Hatt1 & $\mathrm{K} 44 \mathrm{~B} / 40 \mathrm{KD}$ & K53D & $60 \mathrm{~KB}$ \\
\hline L-05 Hatt1 & K25D/66GD & K30D & $45 \mathrm{~KB}$ \\
\hline L-05 Hatt1 & $\mathrm{K} 60 \mathrm{D} / 45 \mathrm{~KB}$ & K45D & $45 \mathrm{GD}$ \\
\hline L-05 Hatt1 & $\mathrm{K} 55 \mathrm{D} / 43 \mathrm{~KB}$ & K80D & $52 \mathrm{GD}$ \\
\hline L-05 Hatt1 & $\mathrm{K} 58 \mathrm{D} / 44 \mathrm{~KB}$ & K55D & 46GD \\
\hline L-05 Hatt1 & $\mathrm{K} 56 \mathrm{D} / 45 \mathrm{~KB}$ & K65D & $50 \mathrm{GD}$ \\
\hline L-05 Hatt1 & $\mathrm{K} 54 \mathrm{D} / 46 \mathrm{~KB}$ & K37D & 60GD \\
\hline L-05 Hatt1 & $\mathrm{K} 57 \mathrm{D} / 45 \mathrm{~KB}$ & K46D & $67 \mathrm{GD}$ \\
\hline L-05 Hatt1 & $\mathrm{K} 58 \mathrm{D} / 43 \mathrm{~KB}$ & K40D & $57 \mathrm{GD}$ \\
\hline
\end{tabular}

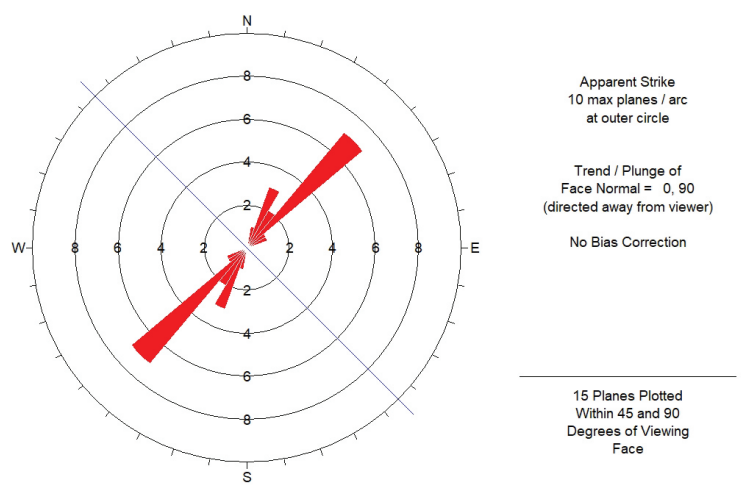

Şekil 3. Süreksizliklerin gül düyagramı.

Figure 3. Rose diagram of the discontinuities.
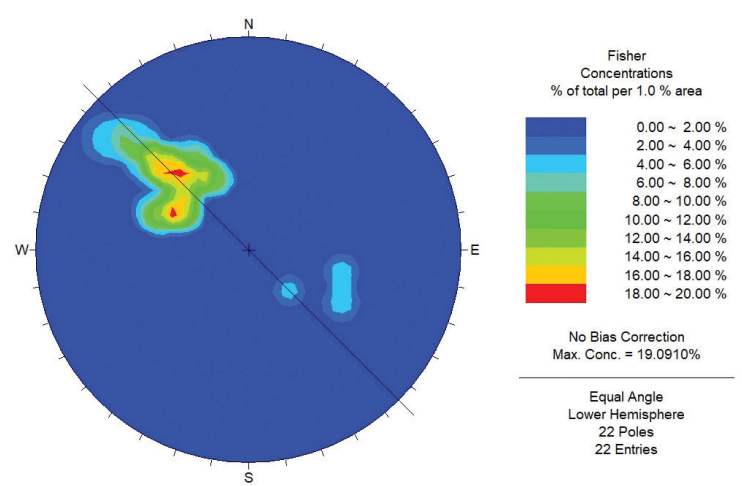

Şekil 4. Tabaka doğrultu ve eğim açılarının eşit alan (Schmidt net) diyagramında gösterimi.

Figure 4. Drawing the layer direction and slope angles at the equal area (Schmidt net) diagram.

Ceylan formasyonu kalkerli kiltaş1, killi kireçtaş1, kalkarenit, taban kısmında ise killi çakıllı kumtaşı ve kumlu kiltaşlarından oluşmaktadır. Bu kayaçlar ince tüf ara düzeyleri içerir.

\section{HIDDROJEOLOJI}

Çalışma alanının büyük kısmını oluşturan Trakya formasyonu hidrojeolojik olarak geçirimsiz-az geçirimli özelliğe sahiptir. Sahanın batı tarafinda Trakya formasyonu üzerinde yer alan Ceylan formasyonu'nda ise genel olarak kil baskın olup geçirimsiz özelliktedir. Ancak tabana yakın kesimleri çakıl ve kum katkılı olup kısmen geçirimli olabilmektedir. Trakya formasyonu içinde yapılan basınçlı su deneylerinde Lugeon değerleri ağırlıklı olarak geçirimsiz ( $<1$ Lugeon), çok az bir kısmı ise az geçirimli olarak (1-5 Lugeon) tespit edilmiştir. Kazı sırasında genel olarak çalışmaları güçleştirecek yeraltı suyu akımıyla karşılaşılması beklenmemektedir. Ancak kumtaşının baskın olduğu düzeylerde, kayacın çok kırıklı veya parçalı olduğu zayıflık zonlarında beklenilenin üzerinde yeraltı suyu 
sızıntılarıyla karşılaşılabilinir. Özellikle, Ceylan formasyonu ile Trakya formasyonu'nun dokanağında yer alan kum-çakıl seviyelerinde, az da olsa yeraltı suyu ile karşılaşılması beklenmektedir. Tünel güzergahını oluşturan kayaç biriminin geçirimlilik özellikleri ve tünellerin sı ̆g derinlikte yer alıyor olması nedeniyle, tünel kazılarında genel olarak damlama veya zayıf sızıntılar halinde yeraltı suyu ile karşılaşılması beklenmektedir.

\section{TÜNEL KAZISI}

Tüneller geometri ve gabarilerine göre NATM veya TBM ile açılmaktadır. Peron, makas, makas bağlantıları ve paralel tüneller arası acil kaçış bağlantı tünelleri başta olmak üzere, gerekli görülen yerlerde tünellerin bir kısmının NATM yöntemiyle; güzergah ana hat tünellerinin ise mekanize olarak TBM yöntemiyle aç1lması mümkündür. (Artson Geoteknik, 2016a, b). Kabataş-Mecidiyeköy metro projesinde her iki yöntemle açılan tünel kazılarının metrajları şöyledir;

1.Hat; $\mathrm{km}: \quad 0+087.811$ ile $\mathrm{km}$ : $0+764.189,1+991.189$ ile $2+212.189, \quad \mathrm{~km}$ : $3+390.080$ ile $3+610.080$ ve $\mathrm{km}: 4+350.199$ ile $5+703.478$ arasi;

2. Hat boyunca ise $\mathrm{km}: 0+85.018$ ile $\mathrm{km}$ : $0+824.982,2+005.982$ ile $\mathrm{km}: 2+226.982, \mathrm{~km}$ : $3+377.182$ ile $\mathrm{km}: 3+59.182$ ve $\mathrm{km}: 4+304.982$ ile km: 5+645.222 arasındaki kısımlar NATM yöntemi kullanılarak açılmaktadır. Bununla birlikte;
1. Hat; km: 0+764.189 ile km: 1+991.189, $\mathrm{km}: 2+212.189$ ile $3+390.080$ ve $\mathrm{km}: 3+610.080$ ile km: $4+350.189$ arası;

2. Hat; km: $0+824.982$ ile km: $2+005.982$, $\mathrm{km}$ : $2+226.982$ ile $\mathrm{km}: 3+377.182$ ve $\mathrm{km}$ : $3+597.182$ ile $\mathrm{km}: 4+304.982$ aras1 kisimlar TBM kullanılarak açılmaktadır.

NATM yöntemi; kazı sonrası oluşacak deformasyonun bir kısmının ana kayaya, bir kısmının ise tahkimat elemanına taşıttırılması esasına dayanmaktadır. $\mathrm{Bu}$ yöntemde asıl olan kazı sonrası, ilk destek oluşturulana kadar geçen zamandır. Bu yöntemin en önemli ilkesi; kayacın direncini korumak ve harekete geçirmek; tünel çevresindeki kayaçta kendini destekleyen genişçe bir halka oluşturmaktır. Bunun için ilk iksa, kayanın kendisinin desteklemesine yardımc olması amacıyla yerleştirilir ve zamanlaması çok önemlidir. Ayrıca iksada birikecek gerilmedeki jeoteknik ölçümlerin düzenli olarak yapılması ile potansiyel tehlikelerin önüne geçilmesinde ve zamanında önlem alınabilmesinde ayrıca bir öneme sahiptir. Tünellerde kazı esas olarak, üst yarı ve alt yarı olmak üzere iki kısımda yürütülmektedir. İstanbul Metrosu Tünelleri gidiş-dönüş olarak, iki ayrı hat olarak açılmakta olup; dört ayrı özellikte tünel kesiti kullanılmaktadır. Bunlar; A (Ana Hat Tünelleri), $\mathrm{P}$ (Peron Tünelleri), T (Makas Tünelleri) ve $\mathrm{B}$ Tipi (Bağlantı Tünelleri) tünellerdir. A tipi, P tipi, T tipi, B tipi tünellerde kazılar üst yarı ve alt yarı kazı olmak üzere iki kademede açılmaktadır (Şekil 5). Ancak T tipi tünellerin kesit alanının fazla büyük olması nedeniyle; diğer tünel tiplerinden farklı olarak sadece T tipinde üst yan; kendi içinde iki ve alt yan ve tek olmak üzere, toplam üç aşamada kazılır. 
Özçelik
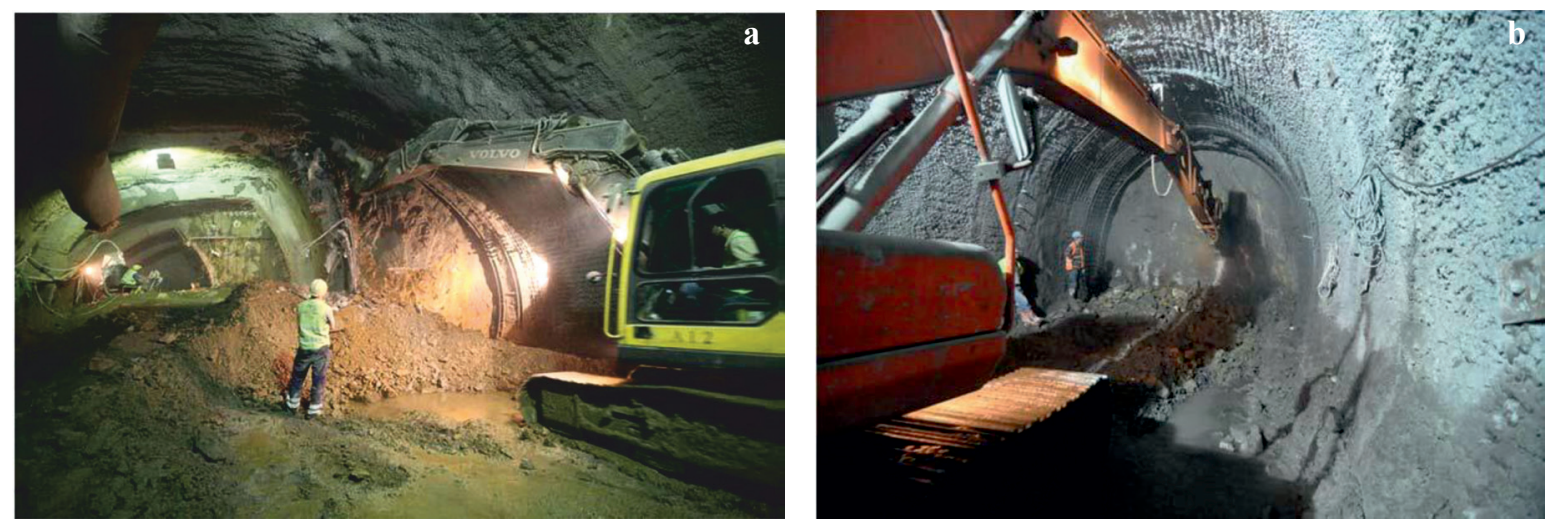

Şekil 5. Üst yarı (a) ve alt yarı kazı (b) olmak üzere iki kademede yapılan tünel kazıları.

Figure 5. Tunnel excavations in two levels, upper half (a) and lower half (b) excavation.

TBM' ler mekanize şekilde tünel açarak ilgili istasyonlara ulaştırılmaktadır. TBM'lerin istasyonlar içinden kazı yapmadan geçebilmeleri için şaft, peron tünelleri, makas tünelleri ve bağlantı tünelleri NATM yöntemiyle daha önceden açılmaktadır. Peron tünellerinin nihai beton kaplamalarından invert betonları TBM' ler tünelden geçmeden; kemer betonları ise peron tünellerinden TBM' ler geçtikten sonra yapılmaktadır. İçinden TBM geçmesi söz konusu olmayan NATM tünellerde ise kazı aşaması ve iksa işleri tamamlandıktan sonra ilgili diğer tünel kazılarını aksatmayacak şekilde nihai beton kaplamaları yapılmaktadır. Kısıtlı zaman içinde TBM' lerin geçeceği istasyonların TBM çalışma programını aksatmayacak biçimde peron tünellerinin kazı ve destekleme işlerinin yapılabilmesi için uygun yerler tespit edilerek NATM tünel işletme şaftları açılmakta ve ulaşım tünelleriyle peron tünellerinin yapılacağ1 kısımlara erişilebilmektedir. Proje kapsamında şaft yerlerinden başlanmak üzere şaftlar açılmakta ve ulaşım tünellerinin yapımını takiben peron tünelleri imal edilerek ve taban (invert) beton kaplama işleri tamamlanmaktadır.

\section{ZEMIN KOŞULLARI}

Yeraltı kazılarının güvenli ve ekonomik şekilde gerçekleştirilmesi, kazı sırasında karşılaşılacak kaya ve zemin koşullarının önceden doğru şekilde tespit edilmesi ve sinıflandırılmasıyla mümkündür. İnceleme alanında esas olarak Trakya formasyonu ile birlikte sahanın batı tarafında dar bir alanda Ceylan formasyonu yer almaktadır. Ceylan formasyonu ağırlıklı olarak kalkerli kil - kiltaşları ve özellikle aynı formasyonun tabanında olmak üzere çakıllı killi kum ve çakıllı kumlu kiltaşlarından oluşmaktadır. Genel olarak zayıf çimentolanmış olan birim, göreceli olarak taban kesiminde daha zayıf çimentolanmıştır. Trakya formasyonu genel olarak kumtaş1, silttaşı, çamurtaş1 ve kiltaş1 seviyelerinin ardalanmasından oluşur ve bu farklı litolojilerin her biri, yer yer daha baskın konumdadır. Ardalanma nedeniyle, Trakya formasyonu farklı litolojik seviyeler yerine, ayrışma düzeylerine göre gruplandırılmıştır.

Litolojik olarak üstte yer alan Ceylan formasyonu, mühendislik özellikleri açısından zayıf çimentolanmış sert zemin olarak değerlendirilmiştir. Trakya formasyonu ise mühendislik özellikleri açısından, tamamen 
ayrışmış (W5), çok - orta derecede ayrışmış (W3-W4) ve az ayrışmış - ayrışmamış (W1W2) kayaç olmak üzere 3 seviye halinde dikkate alınmıştır. Tamamen ayrışmış kayaç seviyesi zemine dönüşmüş, diğer iki seviye ise kayaç olarak değerlendirilmiştir. Tünel güzergahını oluşturan farklı zemin - kayaç ortamlar aşağıda ayrıntılı olarak ele alınmıştır.

\section{ZEMIN TABAKALARININ TÜNEL KAZISI AÇISINDAN SINIFLANDIRILMASI}

Açık kazı veya tünel kazı kotlarında karşılaşılması beklenen Ceylan formasyonunun zemin niteliğindeki kısımları ile tamamen ayrışmış kayaç özelliğinde olan kısımları bu bölümde konu edilmiştir (Çizelge 2). Birleştirilmiş Zemin Sınıflaması'na (USCS) ek olarak, tünel mühendisliğinde zeminler kütlesel dayanım ve permeabiliteleri ile bunlara bağl özellikleri açısından da sınıflandırılmaktadır. Bu bakımdan Terzaghi (1950), Huer (1974), Huer ve Virgens (1987), Deere vd. (1969) tarafindan geliştirilen zemin sınıflamaları dikkate alınarak, tünel kazısı zemin tabakaları için yapılan sınıflandırma Çizelge 3'de verilmiştir.

Çizelge 2. L2 Bağlantı tünel kazısında karşılaşılan Ceylan formasyonu.

Table 2. Ceylan formation encountered in L2 connection tunnel excavation.

\begin{tabular}{cccc}
\hline $\begin{array}{c}\text { Mesafeden } \\
(\mathrm{km})\end{array}$ & $\begin{array}{c}\text { Mesafeye } \\
(\mathrm{km})\end{array}$ & $\begin{array}{c}\text { Aradaki uzunluk } \\
(\mathrm{m})\end{array}$ & Jeolojik birim \\
\hline $0+440$ & $0+650$ & 190 & Ceylan \\
$1+000$ & $1+700$ & 700 & Formasyonu \\
\hline
\end{tabular}

Çizelge 3. Güzergahtaki zemin seviyelerinin tünelcilik açısından sınıflandırılması.

Table 3. Classification of the soil layers along the alignment from tunneling point of view.

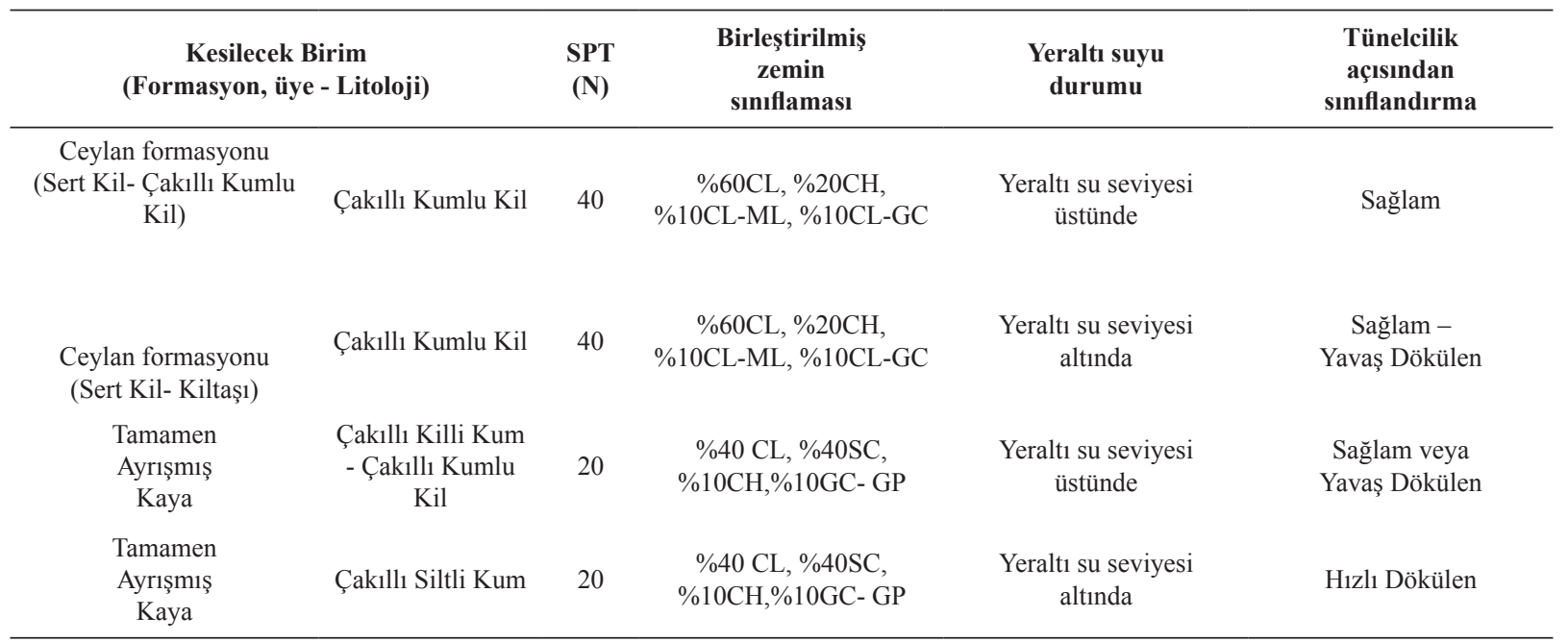


Özçelik

\section{Zayıf Zeminde Kazı}

Kazı öncesi zemin, enjeksiyon veya jet grouting ile sağlamlaştırılarak geçirimsiz hale getirilmektir. Kazı, kırıcı uçlu makinalar yardımıla (Jack Hammer) yapılmaktadır. Ancak, kazı Kalot-Stros-Radye kademeleri halinde ve kısa adımlarla yürütülmektedir.

\section{Orta Sertlikteki Zeminde Kazı}

Orta sertlikteki zeminde kazı kırıcı uçlu makinalarla (Jack Hammer) yapılmaktır. İki aynada bir kazı makinası ve delici makina (Jumbo) planlanmıştır. Bir aynada kazı ve kazı malzemesi nakli yapılırken, ikinci aynada çelik hasır, iksa, püskürtme beton (shotcrete) ve blonlama ile destekleme yapılmaktır. Kazı zemini izin verdiği ölçüde tam kesit olarak açılmaktadır. $\mathrm{Bu}$ durum ulaşım yönünden büyük kolaylık sağlamaktadır. Olumsuz koşullarda zemin kademeli kazılacak ve halka (tünel kesiti) en kısa zamanda tamamlanacaktır. Ayrıca, gerektiğinde aynada, aynanın gelmemesi (stabilitesinin bozulmamas1) için ayna göbeği bırakılmaktadır. Kazı malzemesi, geniş ölçüde oluşturulacak manevra ceplerinden yararlanılarak kamyonla şaft altına nakledilmektedir. Bu tip zeminlerde kırıcı uçlu makinalarla günlük ilerleme hızı ortalama $1-1.5$ m'dir.

\section{Sert Zemin Kazısı}

Tünellerde ortaya çıabilecek ve Jack Hammer ile kazilmaya izin verilmeyen zeminlerde, zemin denetimli olarak dinamit ile kazılarak aynı şekilde nakledilecektir. Sert zeminlerde günlük ilerleme hızı ortalama 1.5 - 2 m'dir.

\section{KAYAÇ SEVIYYELERININ TÜNEL KAZISI AÇISINDAN SINIFLANDIRILMASI}

Tünel çalışmalarında ve kayaç kazı işlerinde, kayacın kütle özelliği dikkate alınmaktadır. Yeraltı kazılarında yaygın olarak kullanılan üç önemli kayaç sınıflaması vardır. Bu sınıflamalar; Kaya Kalite İndeksi (Q), Eklemli Kaya Kütlelerinin Jeo-mekanik Sinıflaması (RMR) ve Jeolojik Dayanım İndeksi (GSI) sınıflamasıdır. Q-sınıflamasında, Q-değeri 0,001 ile 1000 arasında değerler almakta olup, en kötü kaya koşulu ile mükemmel kaya arasını kapsamaktadır. Benzer şekilde, 0-100 aralığında değişen puan sistemine dayalı RMR sınıflaması, çok iyi ile çok kötü olmak üzere 5 kaya sınıfını tanımlar. GSI sınıflamasında ise, kayaç kütlesinin yapısal özelliğine bağlı olarak 5, çatlakların durumu ve ayrışma derecesi açısından (süreksizlik yüzey koşuluna bağlı olarak) ise 5 olmak üzere toplam $(5 \times 5) 25$ kategori içinde sayısal olarak ifade edilmektedir. GSI siniflaması, en kötüden en iyi kayaç koşuluna uygulanabilirliği nedeniyle günümüzde özellikle mühendislik değerlendirmeleri açısından RMR sınıflamasına tercih edilmektedir. Başlangıçta RMR ve Q sınıflandırma puanları ile ilişkilendirilen GSI, daha sonraki yıllarda yapılan değişikliklerle 1999'dan sonra tek başına bir sınıflandırma sistemi olarak kullanılmaktadır (Barton vd., 1974; Hoek ve Brown, 1980; Hoek, 2000; Ulusay ve Sönmez, 2000).

Saha gözlemleri, yeraltı suyu durumu ve laboratuvar deneylerinden elde edilen jeoteknik veriler (Çizelge 4) birlikte değerlendirilerek, tünel güzergahındaki kaya ortamlarının (Çizelge 5 ve 6) litoloji ve farklı ayrışma düzeyleri dikkate alınarak Q, RMR ve GSI kayaç kütle sınıflama sistemlerine göre sınıflandırılmıştır. RMR sınıflandırması Bieniawski (1993)'e göre yapılmıştır. Sınıflamada yeraltı su puanı, 
eklemlerdeki su basıncı/en büyük asal gerilim (sı̆g tüneller için en büyük asal gerilim = düşey gerilim kabul edilir), oranına göre belirlenmiş, süreksizlik yönelim düzeltmesi için ise (-5) orta değeri alınmıştır (Hoek ve Brown, 1980; Hoek, 2000). RMR puanı; tünel için, süreksizlik düzeltmesi yapılarak ve GSI değerlerinin belirlenmesine yönelik olmak üzere üç şekilde hesaplanmıştır. GSI değerinin belirlenmesine yönelik RMR hesaplamasında, yeraltı su durumu için "15" (tamamen kuru), süreksizlik yönelim düzeltmesi için ise "0" (çok uygun) puanı dikkate alınmıştır. GSI değerleri, sahada yeterli kaya mostraları görülememiş olması nedeniyle RMR ve $\mathrm{Q}$ değerlerinden, yukarıda verilen bağıntılar kullanılarak belirlenmiştir. Sınıflandırma sonuçları Çizelge 7'de verilmiştir.

Çizelge 4. Tünel güzergahındaki jeolojik birimlerin jeoteknik özellikleri (Artson Geoteknik, 2016 a,b).

Table 4. Geotechnical characteristics of the geological units along the tunnel alignment (Artson Geotechnic, 2016 a,b).

\begin{tabular}{|c|c|c|c|c|c|c|c|}
\hline \multirow{4}{*}{ Jeolojik birim } & \multirow[t]{4}{*}{ zellikleri } & \multicolumn{6}{|c|}{ Jeoteknik Parametreler } \\
\hline & & \multirow[b]{2}{*}{ Birim hacim ağırlığı } & \multicolumn{3}{|c|}{ Dayanım Parametreleri } & \multicolumn{2}{|c|}{ Deformasyon Parametreleri } \\
\hline & & & $\begin{array}{c}\text { Kohezyon } \\
\text { c }\end{array}$ & $\begin{array}{c}\text { Tek eksenli } \\
\text { basınç dayanımı }\end{array}$ & $\begin{array}{c}\text { İçsel sürtünme açısı } \\
\varnothing\end{array}$ & $\begin{array}{c}\text { Young modülü } \\
\mathbf{E}\end{array}$ & $\begin{array}{c}\text { Poisson } \\
\text { oranı } \\
v\end{array}$ \\
\hline & & $\mathbf{k N} / \mathbf{m}^{3}$ & $\mathbf{k P a}$ & MPa & $(\circ)$ & $\mathbf{N} / \mathbf{m}^{2}$ & \\
\hline \multirow{4}{*}{$\begin{array}{c}\text { Ceylan } \\
\text { Formasyonu }\end{array}$} & Sert kil & $26.0-27.7$ & & $18-28$ & & & $0.12-0.28$ \\
\hline & Sert kil- kiltaş1 & $28.6-28.9$ & & $67-185$ & $30-34$ & & $0.16-0.22$ \\
\hline & Killi kum & $24.5-27.4$ & & $32-47$ & $20-26$ & & $0.23-0.30$ \\
\hline & Kumlu kil & $27.8-28.0$ & $18-20$ & $15-18$ & $11-15$ & & $0.14-0.20$ \\
\hline \multirow{3}{*}{$\begin{array}{c}\text { Trakya } \\
\text { Formasyonu }\end{array}$} & Kumtaş1 & $26.3-28.4$ & & $40-165$ & $40-56$ & $4.9-5.40$ & $0.23-0.29$ \\
\hline & Silttaş1 & $23.5-27.6$ & & $15-25$ & $30-35$ & & $0.28-0.26$ \\
\hline & Kiltaşı & $23.4-27.6$ & & $12-17$ & $20-55$ & $1.90-4.58$ & $0.20-0.24$ \\
\hline
\end{tabular}

Çizelge 5. Mecidiyeköy - Kabataş Metro hattında NATM yöntemi ile kazılan jeolojik formasyon (başlangıçtan Kabataş istasyonuna kadar olan tünel bölümü).

Table 5. Geological formation excavated by NATM method in Mecidiyeköy - Kabataş subway line (tunnel section from the beginning to Kabataş station).

\begin{tabular}{cccc}
\hline Mesafeden $(\mathrm{km})$ & Mesafeye $(\mathrm{km})$ & Aradaki uzunluk $(\mathrm{m})$ & Jeolojik birim \\
\hline $0+000$ & $0+240$ & 240 & \\
$0+240$ & $0+460$ & 220 & Trakya formasyonu \\
$4+437$ & $4+658$ & 221 & 707 \\
$4+568$ & $5+365$ & & \\
\hline
\end{tabular}

Çizelge 6. Mecidiyeköy - Kabataş Metro hattında TBM yöntemi ile kazılan jeolojik formasyon (Kabataş İstasyonu - Mecidiyeköy şaftı arasındaki tünel bölümü).

Table 6. Geological formation excavated by TBM method in Mecidiyeköy - Kabataş subway line (tunnel section between the Kabatas Station and Mecidiyeköy Shaft).

\begin{tabular}{cccc}
\hline Mesafeden $(\mathbf{k m})$ & Mesafeye $(\mathbf{k m})$ & Aradaki uzunluk $(\mathbf{m})$ & Jeolojik birim \\
\hline $0+460$ & $2+079$ & 1619 & \\
$2+079$ & $2+300$ & 221 & Trakya formasyonu \\
$2+300$ & $3+425$ & 1125 & \\
$3+425$ & $3+646$ & 221 & \\
$3+646$ & $4+437$ & 791 & \\
\hline
\end{tabular}


Özçelik

Çizelge 7. Tünel güzergahındaki kayaların litoloji ve ayrışma derecelerine göre sınıflandırılması (Artson, Geoteknik 2016 a,b). Table 7. Classification of rocks along the tunnel alignment according to lithology and weathering degrees (Artson Geotechnic, $2016 a, b)$

\begin{tabular}{|c|c|c|c|c|c|}
\hline Kaya birimi & Kaya özellikleri & $\mathbf{Q}$ & RMR & GSI & ÖNORM B 2203-1 \\
\hline $\begin{array}{c}\text { Trakya formasyonu } \\
\text { Çok - Orta Derecede Ayrışmış Kayaç } \\
\text { (W3-W4) }\end{array}$ & $\begin{array}{l}\text { Ağırlıklı silttaşı olmak üzere, kiltaşı } \\
\text { - kumtaşı - silttaş1 ardalanması } \\
\text { (parçalı) }\end{array}$ & $\begin{array}{l}0.08 \\
\text { Çok fazla Zayıf } \\
\text { Kaya }\end{array}$ & $\begin{array}{c}26-31 \\
\text { Zayıf Kaya }\end{array}$ & 30 & $\begin{array}{c}\text { C2 - B 3 } \\
\text { Bask1l1 - Taneli }\end{array}$ \\
\hline $\begin{array}{c}\text { Trakya formasyonu } \\
\text { Az Ayrışmış - Ayrışmamış Kaya } \\
\text { (W1-W2) }\end{array}$ & $\begin{array}{c}\text { Ağırlıklı silttaş1 olmak üzere, kiltaşı } \\
\text { - kumtaş1 - silttaşı ardalanması (sık } \\
\text { çatlaklı - parçalı) }\end{array}$ & $\begin{array}{c}0.31 \\
\text { Çok Zayıf Kaya }\end{array}$ & $\begin{array}{c}31-36 \\
\text { Zayıf Kaya }\end{array}$ & 40 & $\begin{array}{c}\text { B3 } \\
\text { Bask111 }\end{array}$ \\
\hline
\end{tabular}

\section{KAZI SIRASINDA OLUSAAN GÖÇÜK}

İstanbul'un Avrupa yakasında geniş alanları kaplayan kumtaşı, silttaşı ve kiltaşından oluşan Trakya formasyonunda ayrışma derinlikleri, dayklar, eklemler, kiltaşının yetersiz taşıma gücünden dolayı kazı mekaniği açısından sorunludur. Ayrıca, Trakya formasyonu yoğun olarak faylanmış ve kıvrımlanmıştır (Şekil 6 ve7). Bu nedenle, temel kazlları ile fay ve kıvrım gibi yapıların uygun olmayan doğrultu ve eğimleri sorunlara neden olmaktadır. NATM kullanılan projenin bu kesiminde tüneller, makas tüneli T tipi olarak açılmakta ve 14.50 m'ye kadar genişlemektedir. Yükseklikleri 9.80 m'ye çıkarken, tünellerin yeryüzü ile arasında kalan zemin kesiti yaklaşık 11.00 m'ye inmektedir. Ayrıca makas tünellerinin yanı sıra ana tünellerin de imalatları yapılmaktadır. Dar bir alanda açılan bu tünellerde, sı̆̆ örtü yükü, değişken ve suya doygun zemin koşulları, ortamdaki gerilme dağılımının değişmesi ve birincil destek sisteminin özelliklerine bağlı olarak Beşiktaş Barbaros Bulvarı'nda $3 \mathrm{~m}$ derinliğinde, $75 \mathrm{~cm}$ çapında bir göçük meydana gelmiştir (Şekil 8).

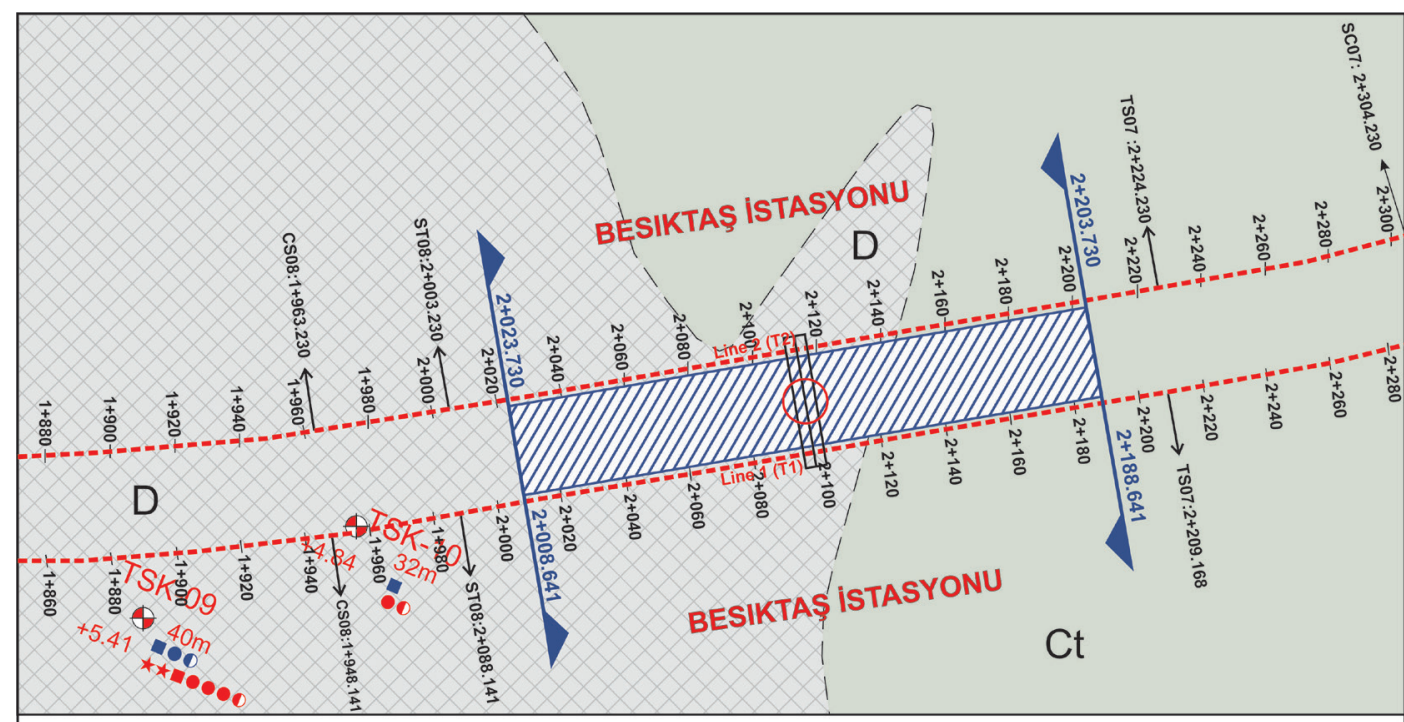

Şekil 6. Tünel güzergahının Beşiktaş istasyonu kesimi (km: $2+023.730$ ile 2 + 203.730) (Artson Geoteknik, 2016 a,b). Figure 6. Besiktass station section of the tunnel alignment (km: $2+023.730$ to $2+203.730)$ (Artson Geotechnic, $2016 a, b)$. 


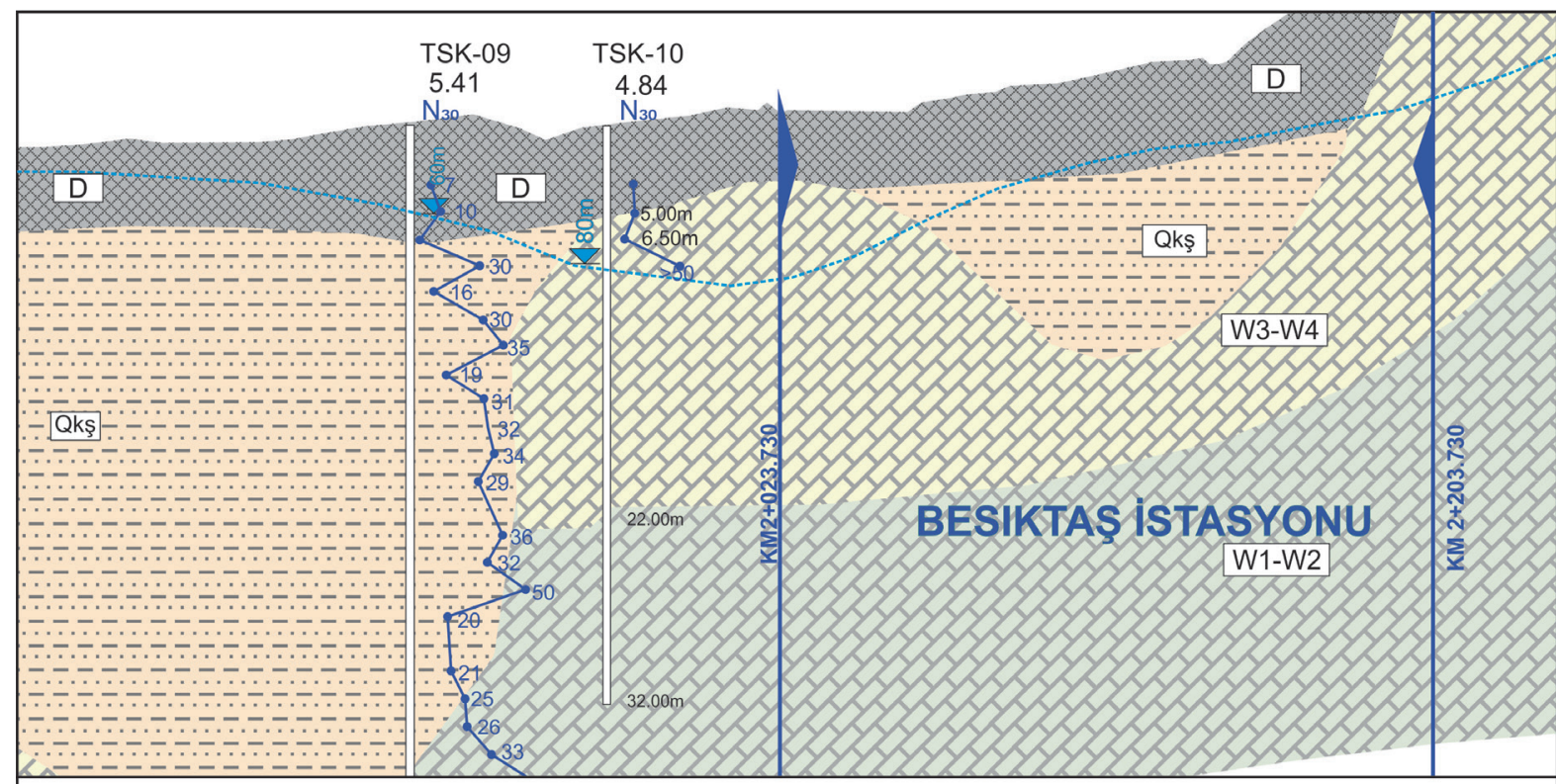

Şekil 7. Beşiktaş istasyonu ve civarının jeolojik kesiti (km: $2+023.730$ ile $2+203.730)$ (Artson Geoteknik, 2016 a, b).

Figure 7. Geological section of Beşiktaş station and its vicinity (km: $2+023.730$ to $2+203.730)$ (Artson Geotechnic, $2016 a, b)$.
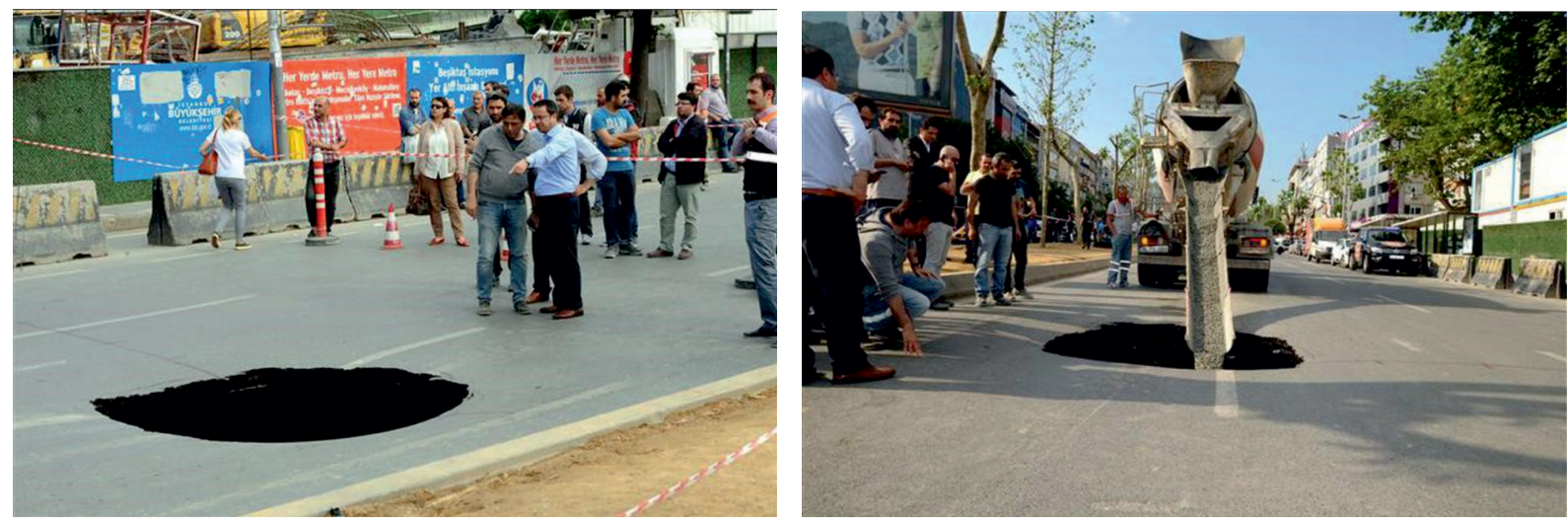

Şekil 8. Beşiktaş Barbaros Bulvarı'nda (Kabataş-Mecidiyeköy Hattı) meydana gelen göçük olayının yüzeydeki hasarlar1.

Figure 8. Damages at the surface due to the collapse occurred at the Besiktas Barbaros Boluevard (KabatasMecidiyekoy Line). 
Özçelik

\section{TARTIŞMA VE SONUÇ}

Kabataş-Mecidiyeköy Tünel kazılarının, hemen hemen tamamına yakınının (asgari \%95'i oranında) Trakya formasyonu içinde, çok az bir kısmı (yaklaşık \%5'i) ise Ceylan formasyonu içinde bulunmaktadır. Ceylan formasyonu kalkerli sert kiltaşlarından oluşmuştur, tabanında çakıl ve kum katkılı seviyeler yer almaktadır. Trakya formasyonu ise, başlıca kumtaşışeyl (kumtaş1, silttaş1, çamurtaşı ve kiltaşı) ardalanmasından oluşmakta ve farklı ayrışma seviyelerini içermektedir. Tünel kazılarında ağırlıklı olarak çok-orta derecede ayrışmış (W3W4) kayaç seviyesi, nispeten daha az oranda ise az ayrışmış (W1) ve ayrışmamış (W2) kayaç seviyelerinin kazılması beklenmektedir. Depo sahası kazılarında ise orta derecede ayrışmış (W3) ve çok ayrışmış (W4) derecede kayaç kazılması beklenmektedir. Trakya formasyonu (kaya birimi) genel olarak kumtaş1, silttaş1, çamurtaş1 ve kiltaşı ardalanmasından oluşmakla birlikte, tünel kazıları sırasında yer yer bu litolojilerden herhangi birinin baskın olduğu kesimlerle de karşılaşılabilmektedir. Trakya formasyonu, yaygın şekilde kıvrımlı ve eklemli olmanın yanı sıra, sıkça makaslanma ve fay zonları ile kesilmiştir. Söz konusu zonlar genellikle parçalanmış-milonitleşmiş ve killeşmiştir.

Tünel güzergahındaki tüm zemin-kayaç seviyeleri mühendislik ve tünel mühendisliği açısından değerlendirilmiş, sınıflandırılmış ve tasarım için zemin parametreleri önerilmiştir. Jeolojik yap1 olarak üstte yer alan Ceylan formasyonu, mühendislik özellikleri açısından sert zemin olarak değerlendirilmiştir. Trakya formasyonu ise mühendislik özellikleri açısından, tamamen ayrışmış (W5), çok - orta derecede ayrışmı̧̧ (W3-W4) ve az ayrışmış ayrışmamış (W1-W2) kayaç seviyeleri olmak üzere üç seviye halinde ele alınmıştır. Tamamen ayrışmış kayaç seviyesi zemin, diğer iki seviye ise kayaç olarak değerlendirilmiştir. Zeminkayaç birimlerine ait jeoteknik parametrelerin değerlendirilmesi sonucunda geçiş zonlarında dikkatli olunması gerekmektedir. Güzergahı oluşturan farklı zemin - kayaç ortamları ayrıntılı olarak ele alınmıştır. Yükseklikleri 9.80 m’ye çıkarken, tünellerin yeryüzü ile arasında kalan zemin kesiti yaklaşık 11.00 m'ye inmektedir. Ayrıca, makas tünellerinin yanı sıra ana tüneller de yapılmaktadır. Dar bir alanda açılan bu tünellerde, sığ örtü yükü, değişken ve suya doygun zemin koşulları, ortamdaki gerilme dağılımının değişmesi ve birincil destek sisteminin özelliklerine bağlı olarak; Beşiktaş Barbaros Bulvarı'nda $3 \mathrm{~m}$ derinliğinde, $75 \mathrm{~cm}$ çapında göçük meydana gelmiştir. Bu nedenle, tünellerin genellikle sı ̆ derinlikte yer almas nedeniyle, özellikle kayanın aşırı ezik olduğu kesimlerde göçük ve dolayısıyla yüzeyde oturma ile çökme tehlikelerine karşı dikkatli olunmalıdır. Otoyollar ve yan yolların altından geçen bu tür tüneller, benzer nedenlerle stabilite açısından kritik dengededir. Kritik yapıların bulunduğu bölgelerin geçişinde kazının kontrollü olarak yapılması, tünel içinde ve yüzeyde özenli şekilde jeolojik-jeoteknik ölçümler yapılması gereklidir. Jeolojik veriler ve kayaçların niteliği çok uygun gözükse bile, tünelin inşası sırasında kazı ve tünel emniyeti için gerekli deformasyon ölçümlerinin uzun süreli olarak mutlaka yap1lmas1 gerekmektedir.

\section{KATKI BELİRTME}

Yazar bu çalışmadaki katkılarından dolayı İstanbul Büyükşehir Belediyesi Raylı Sistem Daire Başkanlığ 1 Avrupa Yakası Raylı Sistem Müdürlüğü, ALSIM ALARKO Sanayi Tesisleri ve Ticaret A.Ş., EMAY Uluslararası Mühendislik ve Müşavirlik, ARTSON Geoteknik Mühendislik 
ve Müşavirlik şirketine teşekkürlerini sunar. Ayrıca, yazar makalenin geliştirilmesindeki değerli katkılarından dolayı editör Prof. Dr. Tamer TOPAL ve hakemlere teşekkür eder.

\section{KAYNAKLAR}

Arıç, C., 1955. Haliç-Küçükçekmece Gölü bölgesinin jeolojisi, Doktora Tezi, İTÜ Maden Fakültesi, İstanbul.

Arığlu, B., Yüksel, A., Arıŏlu, E., 2002. İzmir metro projesi Nenehatun tünelindeki geoteknik çalışmalar ve değerlendirilmesi. ECAS2002 Uluslararası Yapı ve Deprem Mühendisliği Sempozyumu, 14 Ekim 2002, Orta Doğu Teknik Üniversitesi, Ankara, Türkiye. 358-368.

ARTSON Geoteknik (Artson Araştırma Sondajları Mühendislik Ticaret Limitet Şirketi), 2016a. İstanbul Metrosu Kabataş-Mecidiyeköy arası Jeolojik-Jeoteknik etüd raporu. Cilt 1, İstanbul (yayımlanmamış).

ARTSON Geoteknik (Artson Araştırma Sondajları Mühendislik Ticaret Limitet Şirketi), 2016b. İstanbul Metrosu Kabataş-Mecidiyeköy arası Jeolojik-Jeoteknik etüt raporu. Cilt 2, İstanbul (yayımlanmamış).

ÖNORM B 2203-1. 2001. Austrian Standards Institute, Underground works, Part 1: Cyclic Driving. Works contract, Issue 2001-12-01.

Barton, N.R., Lien, R., Lunde, J., 1974. Engineering classification of rock masses for the design of tunnel support. Rock Mechanics and Rock Engineering, 6 (4), 189-236.

Bieniawski, ZT., 1993. Classification of rock masses for engineering: The RMR system and future trends. Comprehensive Rock Engineering Pergamon, 3, $553 \mathrm{~s}$.

Dalgıç, S., 2004. Factors affecting the greater damage in the Avc1lar area of Istanbul during the 17 August 1999 Izmit Earthquake. Bulletin of the International Association for Engineering Geology and the Environment, Bulletin of Engineering Geology and Environment, (63) $221-232$.
Deere, D.U., Peck, R.B., Monsees, J.E., Schmidt, B., 1969. Design of tunnel liners and support systems, Report to UMTA, DOT, available through NTIS.

Deere, D.U., Merrift, A.H., Cording, E.J., 1974. Engineering geology and underground construction. 2nd International Congress of Engineering GeoIogy, Sao Paulo, Brasil, 18-24 August, 1974.

Güven, G., 2009. İstanbul metrosu Otogar-Kirazlı 1 arasının mühendislik jeolojisi ve tünel kazılarına bağlı oluşan deformasyonların değerlendirilmesi, Yüksek Lisans Tezi, İTÜ Fen Bilimleri Enstitüsü, Jeoloji Mühendisliği Programı, İstanbul (yayımlanmamış).

Hoek, E., Brown, E.T., 1980. Underground excavations in rock. Institutions of Mining and Metallurgy. London, $382 \mathrm{~s}$.

Hoek, E., 2000. Kaya Mühendisliği. TMMOB Maden Mühendisleri Odası Yayını, Ankara, 319 s.

Ketin, İ., 1991. İstanbul ve dolayının jeoloji haritası. İSKİ, İstanbul (yayınlanmamış).

Seymen, İ., 1995. İzmit Körfezi ve çevresinin jeolojisi, İzmit Körfezi Kuvarterner istifi. (ed. Meriç, E.), Kocaeli Valiliği Çevre Koruma Vakfi, Kocaeli.

Terzaghi, K., 1950. Geologic aspects of soft ground tunneling. Chapter 11 in Applied Sedimentation, R. Task and D. Parker, eds. New York, John Wiley \& Sons.

Tunçdemir, H., 1998. Arazi basıncının dengelenmesi esasına göre çalışan tam cephe tünel açma makinelerinin kazı performansını etkileyen zemin özellikleri ve İzmir Metrosu örneği. 4.Ulusal Kaya Mekaniği Sempozyumu, 22-23 Ekim, Zonguldak.

Ulusay, R., Sönmez, H., 2000. Hoek-Brown yenilme ölçütüne ilişkin değişiklik önerileri ve bunların uygulanabilirliği. Jeoloji Mühendisliği Dergisi, 23/24 (1), 1-21. 
